\title{
A porous biochar supported nanoscale zero-valent iron highly efficient for the remediation of cadmium and lead contaminated soil
}

\section{Wei Qian}

Zhongkai University of Agriculture and Engineering

Zeng-Hui Diao ( $\nabla$ zenghuid86@163.com)

Zhongkai University of Agriculture and Engineering

\section{Research Article}

Keywords: Cadmium (Cd), Lead (Pb), Biochar, Nano zero valent iron (nZVI), Contaminated soil, Heavy metals

Posted Date: March 16th, 2021

DOl: https://doi.org/10.21203/rs.3.rs-250897/v1

License: (c) (i) This work is licensed under a Creative Commons Attribution 4.0 International License. Read Full License 
7

8

9

10

\title{
A porous biochar supported nanoscale zero-valent iron highly efficient for the remediation of cadmium and lead contaminated soil
}

\author{
Wei Qian ${ }^{1}$, Zeng-Hui Diao ${ }^{1,2 *}$
}

${ }^{1}$ Zhongkai University of Agriculture and Engineering, Guangzhou 510225, China

(1)

${ }^{2}$ Hong Kong Polytechnic University, Hong Kong

* Corresponding author:

E-mail address: zenghuid86@163.com (Z.H. Diao). 


\section{Abstract}

Risk associated with heavy metals in soil has been received widespread attention. In this study, a porous biochar supported nanoscale zero-valent iron (BC-nZVI) was applied to immobilize cadmium $(\mathrm{Cd})$ and/or lead $(\mathrm{Pb})$ in clayey soil. Experiment results indicated that the immobilization of $\mathrm{Cd}$ or $\mathrm{Pb}$ by $\mathrm{BC}-\mathrm{nZVI}$ process was better than that of $\mathrm{BC}$ or nZVI process, and about $80 \%$ of heavy metals immobilization was obtained in BC-nZVI process. Addition of BC-nZVI could increase soil $\mathrm{pH}$ and organic matter ( $\mathrm{SOM}) . \mathrm{Cd}$ or $\mathrm{Pb}$ immobilization was inhibited with coexisting organic compound 2,4-dichlorophenol (2,4-DCP), but 2,4-DCP could be removed in a simultaneous manner with $\mathrm{Cd}$ or $\mathrm{Pb}$ immobilization at low concentration levels. Simultaneous immobilization of $\mathrm{Cd}$ and $\mathrm{Pb}$ was achieved in $\mathrm{BC}-\mathrm{nZVI}$ process, and both $\mathrm{Cd}$ and $\mathrm{Pb}$ availability significantly decreased. Stable $\mathrm{Cd}$ species inculding $\mathrm{Cd}(\mathrm{OH})_{2}, \mathrm{CdCO}_{3}$ and $\mathrm{CdO}$ were formed, whereas stable $\mathrm{Pb}$ species such as $\mathrm{PbCO}_{3}$, $\mathrm{PbO}$ and $\mathrm{Pb}(\mathrm{OH})_{2}$ were produced with BC-nZVI treatment. Simultaneous immobilization mechanism of $\mathrm{Cd}$ and $\mathrm{Pb}$ in soil by $\mathrm{BC}-\mathrm{nZVI}$ was thereby proposed. This study well demonstrates that BC-nZVI has been emerged as a potential technology for the remediation of multiple metals in soil.

Keywords: Cadmium (Cd); Lead (Pb); Biochar; Nano zero valent iron (nZVI);

Contaminated soil; Heavy metals. 


\section{Introduction}

Heavy metal contamination in environment is considered as one of the most serious environmental issues worldwide (Arshadi et al, 2014; Ren et al, 2017; Zama et al, 2017; Yang et al, 2018; Wang et al, 2020). Numerous heavy metals (ie., cadmium $(\mathrm{Cd})$, lead $(\mathrm{Pb})$ and chromium $(\mathrm{Cr}))$ are non-biodegradable, and accumulate in living organisms (Zhou et al, 2014; Weng et al, 2016; Qian et al, 2019; Liu et al, 2020; Yang et al, 2020), which are contaminants with high toxicity to both human beings and ecosystem even at low concentration levels (Kumari et al, 2015; Wang et al, 2019). Particularly, both $\mathrm{Cd}$ and $\mathrm{Pb}$ are widely distributed in water and soil through anthropogenic activities and natural activities (Lee et al, 2009; Diao et al, 2018; Qiu et al, 2020), which are usually used in many industrial applications including storage battery and painting pigment and cause serious water, soil and air pollution (Arshadi et al, 2014; Puga et al, 2015; Ahmad et al, 2016; Awual et al, 2018). They are all listed as human carcinogens according to the US EPA (Tchounwou et al, 2014). Thus, the remediations of $\mathrm{Cd}$ and $\mathrm{Pb}$ contaminated water and soil are urgent.

Up to date, various kinds of remediation techniques have been developed, such as phytoremediation, electrokinetic remediation, chemical precipitation, ion exchange, adsorption and biosorption processes (Ma et al, 2010; Mahar et al, 2015; Zhu et al, 2016). Among these methods, adsorption has been considered as one of the most effective methods for the remediation of heavy metals due to its low cost and high efficiency in use (Cui et al, 2016; Lyu et al, 2018; Wang et al, 2019). Until now, a great deal of adsorbents have been extensively reported, such as clay minerals, 
activated carbons, biochar and nanomaterials (Wang et al, 2014; Qiu et al, 2020). Especially, biochar, a carbon-material produced from pyrolysis of biomass, has been widely applied for heavy metals remediation (Rajapaksha et al, 2016; Ren et al, 2017; Wang et al, 2019). Recently, nano zero valent iron (nZVI) is also considered as one of the most promising remediation materials due to high reactivity (Li et al, 2018; Diao et al, 2020). Numerous studies have well demonstrated that nZVI is effective in remediation of various contaminants in water and soil (Vítkova et al, 2018; Diao et al, 2016; Li et al, 2019). Interestingly, it has been reported that biochar materials are also often used as a support to overcome nZVI aggregation in use (Qian et al, 2017; Liu et al, 2018; Wang et al, 2019), and biochar based iron composites exhibit a superior performance on the remediation of various contaminants (Wang et al, 2019; Zhang et al, 2019).

More recently, a biochar supported zerovalent iron (BC-nZVI) perpared using iron salt and green tea has been reported in our previous work (Liu et al, 2018). But it is still unclear whether $\mathrm{Pb}$ and/or $\mathrm{Cd}$ in soil could be effictively immobilized using this BC-nZVI. So far, most studies focused on investigating the single heavy metal immobilization by biochar based iron composites ( $\mathrm{Su}$ et al, 2016; Liu et al, 2020; Mandal et al, 2020), but little studies investigated on the simultaneous immobilization of multiple heavy metals in soil (Bian et al, 2014; Yin et al, 2016; Qiao et al, 2018). Actually, in addition to multiple heavy metals, organic compounds like 2,4-dichlorophenol might also exist in soil (Ma et al, 2020; Diao et al, 2020), and the heavy metal immobilization of biochar based iron composites is significantly 
dependent on different soil properties (Shen et al, 2016; Qiao et al, 2019). Thus it would be more motivated to exam the coexisting effect of organic compound on multiple heavy metals immobilization by this BC-nZVI. Also, the underlying mechanisms of the simultaneous immobilization of $\mathrm{Cd}$ and $\mathrm{Pb}$ in soil have not been fully explored.

Herein, the aims of the present work are to (1) study the immobilization of $\mathrm{Cd}$ and/or $\mathrm{Pb}$ by $\mathrm{BC}-\mathrm{nZVI}$ at different conditions; (2) examine the variations of soil properties and heay metals bioavailability; (3) determine transformation products of $\mathrm{Cd}$ and $\mathrm{Pb}$ in soil during the reaction; (4) illustrate the simultaneous immobilization mechanism of $\mathrm{Cd}$ and $\mathrm{Pb}$ in soil.

\section{Materials and methods}

\subsection{Materials and chemicals}

The chemicals such as $\mathrm{PbCl}_{2}$ and $\mathrm{CdCl}_{2}$ were purchased from Guangzhou Chemical Reagent Company. All chemicals were of the analytical grade or higher. The detail characterizations of BC-nZVI samples were described by our previous study (Liu et al, 2018). Previous results showed that nZVI particles were regularly formed on the surface of BC (Fig. S1). A kind of unpolluted soil sample (farm soil) was collected at 0-20 cm depth from agricultural field in Foshan city, China. The real $\mathrm{Cd}$ and $\mathrm{Pb}$ contaminated surface soil was collected from a farmland near industrial park site in Qingyuan city, China. All soil samples were dried and filtered through 2 mm sieves (Yang et al., 2016), and their main characteristics were shown in Table S1. For Cd-spiked soil preparation, $\mathrm{CdCl}_{2}$ solution was added to the uncontaminated soil 
$(2 \mathrm{~kg})$ with the solid-liquid ratio $(1: 5, \mathrm{w} / \mathrm{v})$, and the mixture continuously stirred for $120 \mathrm{~h}$. Then the mixture was air-dried (Yang et al., 2016), Cd concentration of the spiked soil was determined using ICP-MS, and it concentration was $9.86 \mathrm{mg} / \mathrm{kg}$. The prepation procedure of $\mathrm{Pb}$-spiked soil was similar to $\mathrm{Cd}$ spiked soil as well as co-spiked soil (ie., $\mathrm{Cd} / \mathrm{Pb}, \mathrm{Cd} / 2,4-\mathrm{DCP}$ and $\mathrm{Pb} / 2,4-\mathrm{DCP}$ ).

\subsection{Experimental procedure}

Batch experiments were conducted with a set of $50 \mathrm{~mL}$ centrifuge tubes containing $6 \mathrm{~g}$ of $\mathrm{Cd}$ and/or $\mathrm{Pb}$ spiked soil and $30 \mathrm{~mL}$ of $\mathrm{BC}-\mathrm{nZVI}$ under anaerobic condition. Then these centrifuge tubes was placed on a rotator at $50 \mathrm{rpm}$ to react for $16 \mathrm{~h}$. At predetermined time intervals, nearly $100 \mathrm{mg}$ of soil suspension were taken out, and separated by centrifugation for further analysis. Also, the supernatant was further filtered for further analysis. The blank experiments were carried out with the absence of BC-nZVI at equal conditions. Generally, the farm spiked soil was used to explore immobilization of $\mathrm{Cd}$ and/or $\mathrm{Pb}$. The reaction conditions were set as following: $[\mathrm{Cd}]_{0}=9.86 \mathrm{mg} / \mathrm{kg},[\mathrm{Pb}]_{0}=101.32 \mathrm{mg} / \mathrm{kg},[\mathrm{BC}-\mathrm{nZVI}]_{0}=2.0 \mathrm{~g} / \mathrm{L}$, soil $\mathrm{pH}=$ $6.54 \pm 0.02$ and reaction time of $16 \mathrm{~h}$. To compare the immobilization performance of different amendments, BC, nZVI and BC-nZVI were used in this study. The effects of BC-nZVI dosages (0.5-3.0 g/L), coexisting organic compound (2,4-DCP) on $\mathrm{Cd}$ and/or $\mathrm{Pb}$ immobilization were investigated, respectively.

\subsection{Analytical methods}

The extracted procedures of both $\mathrm{Cd}$ and $\mathrm{Pb}$ in soil sample were similar to previous study (Qiu et al., 2019). Both $\mathrm{Cd}$ and $\mathrm{Pb}$ concentrations were determined 
according to US EPA method 3050 A (1996), and their five kinds of fractions in soil before and after remediation were determined using sequential extraction procedures (SEP) (Tessier et al, 1979). Total Fe in soil was suffered from acid digestion, and then determined using ICP-MS. The species of elements including $\mathrm{Cd}, \mathrm{Pb}, \mathrm{Fe}, \mathrm{O}$ and $\mathrm{C}$ on soil surface were analyzed by an X-ray photoelectron spectrometer. The extraction and analysis of 2,4-DCP was similar to our earlier study (Diao et al, 2020). The soil $\mathrm{pH}$ was measured by a $\mathrm{pH}$ detector using a solid-liquid ratio $(1: 2.5, \mathrm{w} / \mathrm{v})$. The soil cation exchange capacity (CEC) was measured according to Qiu et al. (2019). Soil organic matter (SOM) was determined according to previous study (Nelson and Sommers, 2001). Soil texture was measured according to Bowman and Hutka (2002). All the analysis was performed in triplicate, and the result was calculated as the average. The statistical analysis was shown in Supplementary Materials.

\section{Results and discussion}

\subsection{Immobilization efficiency of $\mathrm{Cd}$ and $\mathrm{Pb}$ using various}

\section{amendments}

As illustrated in Fig. 1a, the immobilization efficiency of $\mathrm{Cd}$ or $\mathrm{Pb}$ was signficantly dependent on different amendments and reaction time. Within $16 \mathrm{~h}$, the immobilization efficiency of $\mathrm{Cd}$ or $\mathrm{Pb}$ increased as reaction time increased. For $\mathrm{Cd}$, nearly $34 \%$ of $\mathrm{Cd}$ immobilization was obtained using $\mathrm{BC}$, which might be the complexation of oxygen-containing functional groups on BC (Wang et al., 2019; Qiu et al., 2020). A slight increase in Cd immobilization was observed from nZVI, and $49.21 \%$ of $\mathrm{Cd}$ immobilization was achieved, suggesting that nZVI exhibited a better 
preformance on $\mathrm{Cd}$ immobilization than $\mathrm{BC}$. In fact, iron oxide and hydroxide might be formed on nZVI, which was favorable to Cd immobilization (Li et al., 2018). Obviously, compared with $\mathrm{BC}$ and nZVI, BC-nZVI exhibited the highest $\mathrm{Cd}$ immobilization efficiency $(86.49 \%)$. It was clearly demonstrated that a high performance on Cd immobilization by BC-nZVI had been sucessfully obtained. A similar trend was observed in $\mathrm{Pb}$ immobilization, and nearly 30,44 and $80 \%$ of $\mathrm{Pb}$ immobilization were obtained in BC, nZVI and BC-nZVI processes, respectively (Fig. 1b). Also, the highest immobilization efficiency was still obtained from BC-nZVI process, suggesting that oxygen-containing functional groups, iron oxide and iron hydroxide on BC-nZVI contributed to Pb immobilization (Liu and Zhao, 2013). It should be noted that $\mathrm{Pb}$ immobilization by all processes were always lower than $\mathrm{Cd}$ since $\mathrm{Pb}$ concentration was higher than that of $\mathrm{Cd}$. Furthermore, the variations of soil $\mathrm{pH}$ and organic matter (SOM) induced by different amendments were also evaluated (Table S2). The $\mathrm{pH}$ values of all treatments increased when different amendments were added. For $\mathrm{Cd}$ case, $\mathrm{pH}$ values increased from 6.54 for blank to 6.82, 6.68 and 6.79 in the presence of nZVI, BC and BC-nZVI, respectively. This suggests an increase in soil $\mathrm{pH}$ by adding $\mathrm{BC}$ based material, which was mainly associated with the alkaline nature of BC (Qian et al., 2019). This clearly confirmed that BC-nZVI could retard the soil acidity. For nZVI treatment, nZVI could also increase soil $\mathrm{pH}$, which was mainly attributable to nZVI corrosion. In fact, the hydrolysis of $\mathrm{Cd}$ ions increased with the increase of soil $\mathrm{pH}$, which subsequently resulted in the formation of Cd oxyhydroxides precipitates, and eventually reduced its mobility and reactivity. 
Similar phenomenon was observed in several pervious studies (Li et al, 2016; Salam et al, 2019). Besides, SOM significantly increased when BC and BC-nZVI were introduced, which could be explained that $\mathrm{BC}$ contains a high organic matter (more than $70 \%$ ) (Qiao et al, 2017). The increase in SOM was farvable for replanting in soil since SOM is the main source of nutrients (Yang et al, 2016). For $\mathrm{Pb}$ case, the variations of $\mathrm{pH}$ and $\mathrm{SOM}$ in soil was similar to that of $\mathrm{Cd}$. Overall, BC-nZVI treatment was the most efficient method for $\mathrm{Cd}$ and $\mathrm{Pb}$ immobilization as well as soil $\mathrm{pH}$ and SOM increase.

\subsection{Effect of $\mathrm{BC}-\mathrm{nZVI}$ dosage on $\mathrm{Cd}$ and $\mathrm{Pb}$ immobilization}

As shown in Fig. 2, the immobilization efficiencies of both $\mathrm{Cd}$ and $\mathrm{Pb}$ increased when the BC-nZVI dosage increased. Nearly 49, 71, 86 and $90 \%$ of $\mathrm{Cd}$ immobilization were found when BC-nZVI dosage were 0.5, 1.0, 2.0 and $3.0 \mathrm{~g} / \mathrm{L}$, respectively (Fig. 2a). As expected, more BC-nZVI dosage induced increased available reactive sites (Liu et al, 2020). However, Cd immobilization only increased from 86.19 to $90.12 \%$ when BC-nZVI dosage increased from 2.0 to $3.0 \mathrm{~g} / \mathrm{L}$. Additionally, $\mathrm{Pb}$ immobilization significantly increased from 36.35 to $80.14 \%$ when BC-nZVI dosage increased from 0.5 to $2.0 \mathrm{~g} / \mathrm{L}$ (Fig. 2b). Similarly, further increase BC-nZVI dosage did not induce an obvious increase in $\mathrm{Pb}$ immobilization, and about $85 \%$ of $\mathrm{Pb}$ immobilization was obtained at $3.0 \mathrm{~g} / \mathrm{L}$. This suggests that a high BC-nZVI dosage might be a waste, BC-nZVI dosage of $2.0 \mathrm{~g} / \mathrm{L}$ might be an optimal reaction condition for both $\mathrm{Cd}$ and $\mathrm{Pb}$ immobilization. Additionally, the effect of $\mathrm{BC}$ dosage on soil $\mathrm{pH}$ and SOM were also examed (Table S3). As expected, soil $\mathrm{pH}$ 
significantly rose as BC-nZVI dosage increased. $\mathrm{pH}$ values increased from 6.54 for the blank to $6.59,6.67,6.79$ and 6.92 for $\mathrm{Cd}$ treatment when $\mathrm{BC}$ dosage was $0.5,1.0$, 2.0 and $3.0 \mathrm{~g} / \mathrm{L}$, whereas the corresponding values increased from 6.56 for the blank to $6.62,6.71,6.83$ and 6.97 for $\mathrm{Pb}$ treatment, respectively. Meanwhile, the SOM also increased with BC-nZVI dosage increased. Actually, BC, a rich biomass, is favorable to the accumulation and formation of SOM (Qiao et al, 2017; Mandal et al, 2020), leading to a significant increase in SOM.

\subsection{Variation of $\mathrm{Cd}$ and $\mathrm{Pb}$ fractions}

Generally, five fractions of heavy metals such as exchangeable (EX), carbonate (CB)-bound, iron-manganese oxides (OX)-bound, organic material (OM)-bound and residual (RS) fractions exist in soil (Tessier et al, 1979; Lyu et al, 2018). In order to understand the heavy metals availability in soil, SEP analysis was performed to examine the fractions of both $\mathrm{Cd}$ and $\mathrm{Pb}$ before and after remediation (Fig. 3). For $\mathrm{Cd}$ case, Cd species in untreated soil were EX (59.14\%), CB (14.91\%), OX (13.61\%), OM (5.65 \%) and RS (6.69 \%). The EX was considered as the most predominant bound for $\mathrm{Cd}$ with $59.14 \%$ of participation ratio, and the order of $\mathrm{Cd}$ fractions was $\mathrm{EX}>\mathrm{CB}>\mathrm{OX}>\mathrm{RS}>\mathrm{OM}$, suggesting that a high $\mathrm{Cd}$ availability existed in untreated $\mathrm{Cd}$ soil. After remediation, the EX fraction significantly deceased to $10.25 \%$, whereas $\mathrm{CB}, \mathrm{OX}, \mathrm{OM}$ and RS fractions increased to $15.48,20.84,8.20$ and $45.23 \%$, respectively. The RS was regardes as the most predominant bound for $\mathrm{Cd}$ with $45.23 \%$ of participation ratio. Furthmore, higher participation ratios of both $\mathrm{OX}$ and $\mathrm{OM}$ were found in treated soil compared with untreated soil, which might be attributed to both 
sorption and precipitation of $\mathrm{Cd}$ on the BC-nZVI surface through oxygen-containing functional groups and iron oxyhydroxides. These results clearly demonstrate a less availability of Cd was achieved after BC-nZVI treatment. This result was well agreed with earlier studies (Qiao et al, 2017; Ren et al, 2017). Furthermore, the variation fractions of $\mathrm{Pb}$ during the reaction were similar to that of $\mathrm{Cd}$. Before remediation, $\mathrm{Pb}$ species in untreated soil were EX (57.65\%), CB (12.34\%), OX (14.62\%), OM $(7.96 \%)$ and RS $(7.43 \%)$. However, the EX fraction significantly decreased to $12.47 \%$, whereas $\mathrm{CB}, \mathrm{OX}, \mathrm{OM}$ and RS fractions increased to $16.59,21.15,8.90$ and $40.89 \%$, respectively, suggesting that $\mathrm{Pb}$ availability in soil significantly decreased after BC-nZVI treatment procedure. These results mentioned above confirm that BC-nZVI exhibited a high effectiveness for both $\mathrm{Cd}$ and $\mathrm{Pb}$ immobilization in soil.

\subsection{Effect of coexisting organic compound on $\mathrm{Cd}$ and $\mathrm{Pb}$ immobilization}

As we all know, heavy metals and organic compounds are always coexist in emvironment (Ma et al, 2010; Liu et al, 2018). In addition to $\mathrm{Cd}$ and $\mathrm{Pb}$, organic compounds like 2,4-dichlorophenol (2,4-DCP) might also exist in soil since 2,4-DCP is usually considered as an intermediate of pesticides (Ma et al., 2010; Diao et al., 2020). Thus effect of coexisting 2,4-DCP on $\mathrm{Cd}$ or $\mathrm{Pb}$ immobilization was examined. For Cd case, an inhibition effect on Cd immobilization when 2,4-DCP was introduced (Fig. 4a). The immobilization of Cd decreased from 86.49 for the blank case to 84.12 , 64.98 and $47.56 \%$ when 2,4-DCP concentrations were $2.56,6.42$ and $12.31 \mathrm{mg} / \mathrm{kg}$, respectively. It was likely that $\mathrm{BC}-\mathrm{nZVI}$ surface reactive sites were consumed by the 
added 2,4-DCP, leading to less available reactive sites for $\mathrm{Cd}$ immobilization. But it should be worth noting that a negative effect was negligible at low 2,4-DCP concentration, and $83.12 \%$ of $\mathrm{Cd}$ immobilization was observed at 2,4-DCP concentration of $2.56 \mathrm{mg} / \mathrm{kg}$. Meanwhile, the removal of 2,4-DCP was also investigated, and nearly 90,73 and $50 \%$ of 2,4-DCP removal were obtained when its concentrations were 2.56, 6.42 and $12.31 \mathrm{mg} / \mathrm{kg}$, respectively (Fig. 4b). The removal of 2,4-DCP could be mainly due to the adsorption and reduction processes (Jia and Wang, 2012; Diao et al, 2020). This clearly demonstrates that the coexisting 2,4-DCP also could be removed with $\mathrm{Cd}$ immobilization. Additionally, a similar trend appeared on $\mathrm{Pb}$ immobilization, and $\mathrm{Pb}$ immobilization was also inhibited with addition of 2,4-DCP (Fig. 5a). The immobilization of $\mathrm{Pb}$ decreased from 80.14 for the blank case to $75.41,50.27$ and $30.15 \%$ when $2,4-\mathrm{DCP}$ concentrations were $2.56,6.42$ and 12.31 $\mathrm{mg} / \mathrm{kg}$, respectively. Also, nearly 82,53 and $30 \%$ of 2,4-DCP removal were obtained when its concentrations were 2.56, 6.42 and $12.31 \mathrm{mg} / \mathrm{kg}$, respectively (Fig. 5b). It should be pointed out that the negative effect of 2,4-DCP on $\mathrm{Pb}$ immobilization was more serious than $\mathrm{Cd}$ immobilization.

\subsection{Simultaneous immobilization of $\mathrm{Cd}$ and $\mathrm{Pb}$ in soil}

As described above, BC-nZVI could effectively immobilize $\mathrm{Cd}$ or $\mathrm{Pb}$ alone in soil, but $\mathrm{Cd}$ and $\mathrm{Pb}$ might often exist in real contaminated soil (Puga et al, 2015; Li et al, 2018), it was important to investigate the simultaneous immobilization of $\mathrm{Cd}$ and $\mathrm{Pb}$ by $\mathrm{BC}-\mathrm{nZVI}$. The immobilization of $\mathrm{Cd}$ decreased with the increase of $\mathrm{Pb}$ concentrations (Fig. 6a), suggesting that addition of $\mathrm{Pb}$ could inhibit $\mathrm{Cd}$ 
immobilization. The immobilization of Cd decreased from $86.49 \%$ for the blank case to $85.54,66.45,51.61$ and $30.15 \%$ at $\mathrm{Pb}$ concentrations of $10.15,50.27,104.16$ and $201.32 \mathrm{mg} / \mathrm{kg}$, respectively. In fact, the decreased Cd immobilization might be due to

253 the occupation of reactive sites when $\mathrm{Pb}$ was added. But no obvious difference was found in $\mathrm{Cd}$ immobilization at low $\mathrm{Pb}$ concentration $(10.15 \mathrm{mg} / \mathrm{kg})$, and nearly $86 \%$ of $\mathrm{Cd}$ immobilization was also obtained. Meanwhile, the immobilization of $\mathrm{Pb}$ was respectively, suggesting that the simultaneous immobilization of $\mathrm{Cd}$ and $\mathrm{Pb}$ was also monitored (Fig. 6b), about 99, 72, 55 and $30 \%$ of $\mathrm{Pb}$ immobilization were obtained when $\mathrm{Pb}$ concentrations were 10.15, 50.27, 104.16 and $201.32 \mathrm{mg} / \mathrm{kg}$, obtained in BC-nZVI process under certain conditions. Furthermore, the speciation transformation of both $\mathrm{Cd}$ and $\mathrm{Pb}$ was also analyzed (Fig. 7). After remediation, the EX fraction significantly deceased from 59.14 to $13.52 \%$, whereas $\mathrm{CB}, \mathrm{OX}, \mathrm{OM}$ and RS increased to $15.12,18.82,10.96$ and $41.58 \%$ for Cd immobilization, respectively, whereas the EX fraction significantly deceased from 55.04 to $10.07 \%$, whereas $\mathrm{CB}$, OX, OM and RS increased to $15.42,18.35,9.12$ and $47.04 \%$ for $\mathrm{Pb}$ immobilization, respectively. These results confirmed that both $\mathrm{Cd}$ and $\mathrm{Pb}$ availability in soil decreased after BC-nZVI treatment.

\subsection{Transformation products of both $\mathrm{Cd}$ and $\mathrm{Pb}$}

In order to understand the variations of both $\mathrm{Cd}$ and $\mathrm{Pb}$ transformation products in soil using BC-nZVI, the surface element compositions of both $\mathrm{Cd}$ and $\mathrm{Pb}$ were analyzed using XPS. For Cd case, four peaks were observed in the $\mathrm{Cd}\left(3 \mathrm{~d}_{5 / 2}\right)$ region during the reaction (Figs. 8a and 8b). Four peaks located at 406.50, 405.80, 405.05 
and $404.20 \mathrm{eV}$ corresponding to $\mathrm{CdCl}_{2}, \mathrm{CdCO}_{3}, \mathrm{Cd}(\mathrm{OH})_{2}$ and $\mathrm{CdO}$ were found at $8 \mathrm{~h}$, respectively. Nearly $60 \%$ of the components were assigned to stable $\mathrm{Cd}$ species inculding $\mathrm{CdCO}_{3}, \mathrm{Cd}(\mathrm{OH})_{2}$ and $\mathrm{CdO}$, but nearly $40 \%$ was still ascribed to free $\mathrm{Cd}$ species like $\mathrm{CdCl}_{2}$. After $16 \mathrm{~h}$, there were still four peaks in the $\mathrm{Cd}\left(3 \mathrm{~d}_{5 / 2}\right)$ region, and peaks located at $406.50,406.20,405.80$ and $405.05 \mathrm{eV}$ corresponding to $\mathrm{CdCl}_{2}$, $\mathrm{Cd}\left(\mathrm{NO}_{3}\right)_{2}, \mathrm{CdCO}_{3}$ and $\mathrm{Cd}(\mathrm{OH})_{2}$ were observed, respectively. Nearly $80 \%$ of the components were assigned to stable $\mathrm{Cd}$ species inculding $\mathrm{CdCO}_{3}$ and $\mathrm{Cd}(\mathrm{OH})_{2}$, but nearly $20 \%$ was still ascribed to free $\mathrm{Cd}$ species such as $\mathrm{CdCl}_{2}$ and $\mathrm{Cd}\left(\mathrm{NO}_{3}\right)_{2}$. For $\mathrm{Pb}$ case, two peaks were observed in the $\mathrm{Pb}\left(4 \mathrm{f}_{7 / 2}\right)$ region at $8 \mathrm{~h}$, whereas three peaks were found at $16 \mathrm{~h}$ (Figs. 8c and 8d). At $8 \mathrm{~h}$, the peak at $139.00 \mathrm{eV}$ was due to free $\mathrm{Pb}$ species like $\mathrm{Pb}\left(\mathrm{NO}_{3}\right)_{2}$, whereas the peak at $138.40 \mathrm{eV}$ were assigned to stable $\mathrm{Pb}$ species such as $\mathrm{PbCO}_{3}, \mathrm{PbO}$ and $\mathrm{Pb}(\mathrm{OH})_{2}$ (Diao et al, 2018). Only nearly $55 \%$ of the components was still assigned to free $\mathrm{Pb}$ species like $\mathrm{Pb}\left(\mathrm{NO}_{3}\right)_{2}$, but $45 \%$ was ascribed to stable $\mathrm{Pb}$ species. However, about $85 \%$ of the components were assigned to stable $\mathrm{Pb}$ species after $16 \mathrm{~h}$. These results mentioned above clearly also confirmed that both $\mathrm{Cd}$ and $\mathrm{Pb}$ were sucessfully immobilized by $\mathrm{BC}-\mathrm{nZVI}$.

\subsection{Possible immobilization mechanisms}

As mentioned above results, both $\mathrm{Cd}$ and $\mathrm{Pb}$ could be effectively immobilized by BC-nZVI, and proportion of stable compounds were also high up to $80 \%$ within $16 \mathrm{~h}$. To better understand the immobilization mechanisms of both $\mathrm{Cd}$ and $\mathrm{Pb}$ by BC-nZVI, the variation of $\mathrm{Fe}, \mathrm{O}$ and $\mathrm{C}$ species in the soil surface during the reaction were also analyzed by XPS technique. As shown in Fig. 9, the peaks located at 710.70, 711.40, 
713.00, 713.80 and $725.20 \mathrm{eV}$ corresponding to $\mathrm{Fe}_{3} \mathrm{O}_{4}, \mathrm{FeOOH}, \mathrm{Fe}_{2}\left(\mathrm{SO}_{4}\right)_{3}, \mathrm{~K}_{2} \mathrm{FeO}_{4}$ and $\mathrm{Fe}_{2} \mathrm{O}_{3}$ were observed from $\mathrm{Fe} 2 \mathrm{p}$ spectrum druing the reaction, respectively (Diao et al, 2018; Liu et al, 2020). It could be explained that nZVI on BC was converted into iron oxide and hydroxide, which plays a quite important role in immobilization of both $\mathrm{Cd}$ and $\mathrm{Pb}$. Futhermore, $\mathrm{Cd}(\mathrm{OH})_{2}, \mathrm{PbO}, \mathrm{FeOOH}, \mathrm{Fe}_{3} \mathrm{O}_{4}$ and $\mathrm{OH}^{-}$were observed from $\mathrm{O} 1 \mathrm{~s}$ spectrum, whereas $\mathrm{C}=\mathrm{O}, \mathrm{C}-\mathrm{H}$ and $\mathrm{C}-\mathrm{C}$ were found from $\mathrm{C} 1 \mathrm{~s}$ spectrum (Wang et al, 2019; Liu et al, 2020). These results also suggest these groups on BC surface sinificantly contributed to both $\mathrm{Cd}$ and $\mathrm{Pb}$ immobilization in soil.

Based on the observation and several previous studies (Yang et al, 2016; Wang et al, 2019), the reaction mechanism for $\mathrm{Cd}$ and $\mathrm{Pb}$ immobilization in soil by $\mathrm{BC}-\mathrm{nZVI}$ was thereby proposed in Fig. 10. Firstly, BC-nZVI exhibites negative charge through analysis of the Zeta potential (data not shown), free $\mathrm{Cd}$ and $\mathrm{Pb}$ in cation form can be conveniently adsorbed on the BC-nZVI via the electrostatic attraction process. Also, the oxygen-containing functional groups on the BC-nZVI would complex with free $\mathrm{Cd}$ and $\mathrm{Pb}$ to form stable species inculding $\mathrm{CdCO}_{3}, \mathrm{Cd}(\mathrm{OH})_{2}, \mathrm{PbCO}_{3}$ and $\mathrm{Pb}(\mathrm{OH})_{2}$ via the precipitation process. Furthermore, both free $\mathrm{Cd}$ and $\mathrm{Pb}$ also can be adsorbed on the iron oxide and iron hydroxide on BC-nZVI surface due to their flocculation and precipitation properties. It should be noted that, due to the standard potentials of $\mathrm{Cd}$, $\mathrm{Pb}$ and $\mathrm{nZVI}$, the most likely immobilization mechanism of $\mathrm{Cd}$ immobilization by BC-nZVI was the adsorption and precipitation, whereas the corresponding mechanism of $\mathrm{Pb}$ was the adsorption, reduction and precipitation. The main reaction processes can be described by the following Eqs (1-8). 
$317 \quad$ Biochar $+\mathrm{Pb}^{2+} \rightarrow$ Biochar- $\mathrm{Pb}$

$$
\equiv \mathrm{FeO}+\mathrm{Cd}^{2+} \rightarrow \equiv \mathrm{FeOCd}^{+}
$$

$$
\equiv \mathrm{FeOH}+\mathrm{Cd}^{2+}+\mathrm{H}_{2} \mathrm{O} \rightarrow \equiv \mathrm{FeOCdOH}+\mathrm{H}^{+}
$$

$$
\mathrm{Fe}^{2+}+\mathrm{H}_{2} \mathrm{O} \rightarrow \mathrm{FeOH}^{+}+\mathrm{H}^{+}
$$

\subsection{Application in real $\mathrm{Cd}$ and $\mathrm{Pb}$ contaminated soil} practical applicability in real $\mathrm{Cd}$ and $\mathrm{Pb}$ contaminated soil is quite important for BC-nZVI in use. Thus, a kind of real $\mathrm{Cd}$ and $\mathrm{Pb}$ contaminated soil was selected for applicability experiment, which was collected from a farmland near industrial park site in Qingyuan city, China. The main physicochemical properties of real contaminated soil sample were shown in Table S1. Accordingly, the concentrations of immobilization was achieved at the dosage of 1.0 or $3.0 \mathrm{~g} / \mathrm{L}$ (Fig. 11a), suggesting that an efficient remediation of $\mathrm{Cd}$ was obtained at a lower BC-nZVI dosage. For $\mathrm{Pb}$ case, nearly 47.25 and $86.02 \%$ of $\mathrm{Pb}$ immobilization were observed at the dosage of 
induce a higher $\mathrm{Pb}$ immobilization in this real contaminated soil. Additionally, the speciation transformation of both $\mathrm{Cd}$ and $\mathrm{Pb}$ was also investigated (Fig. 11b). After remediation, the EX fraction of Cd significantly decreased from 56.85 to $4.59 \%$ at BC-nZVI dosage of $1.0 \mathrm{~g} / \mathrm{L}$, whereas the RS fraction increased from 10.23 to $49.29 \%$, respectively. Meanwhile, the EX fraction of $\mathrm{Pb}$ decreased from 55.11 to $10.48 \%$ at BC-nZVI dosage of $3.0 \mathrm{~g} / \mathrm{L}$, whereas the RS fraction increased from 8.97 to $40.26 \%$, respectively. These results clearly demonstrate that both $\mathrm{Cd}$ and $\mathrm{Pb}$ availability in real contaminated soil significantly decreased after BC-nZVI treatment. Also, both $\mathrm{pH}$ and SOM in real contaminated soil increased when BC-nZVI was introduced (Table S4), suggesting that the properties of real contaminated soil has been improved. These results confirmed that $\mathrm{BC}-\mathrm{nZVI}$ also can effectively immobilize both $\mathrm{Cd}$ and $\mathrm{Pb}$ in real contaminated soil.

\subsection{Environmental implications and limitations}

The present work well demonstrate that BC-nZVI not only exhibited efficient $\mathrm{Cd}$ or/and $\mathrm{Pb}$ immobilization performance in simulated soil, but also effectively immobilized $\mathrm{Cd}$ and $\mathrm{Pb}$ in real contaminated soil in the short term. These findings could provide an insight into the remediation of multiple heavy metals contaminated soil using biochar based iron materials. Also, the treated contaminated soil can meet the revegetation purpose. However, the used soil textures in this work were typically clayey soils, and other environmental conditions such as the soil textures, the rainfall wash cycles and microbial activity might affect $\mathrm{Cd}$ and/or $\mathrm{Pb}$ immobilization performance. Thus, further studies are needed to exame the immobilization of $\mathrm{Cd}$ 
and/or $\mathrm{Pb}$ in different textures soils as well as the effects of rainfall wash cycles and microbial activity under long-term conditions.

\section{Conclusions}

In this work, the application of biochar supported nanoscale zero-valent iron (BC-nZVI) as an amendment for the $\mathrm{Cd}$ and/or $\mathrm{Pb}$ immobilization in soil was systematically invesigated. Results indicated that BC-nZVI process could effectively immobilize $\mathrm{Cd}$ or $\mathrm{Pb}$ in soil, and the immobilization of $\mathrm{Cd}$ and $\mathrm{Pb}$ were high up to 86.49 and $80.14 \%$, respectively. The increased BC-nZVI dosage not only could induce increase of heavy metals immobilization as well as both soil $\mathrm{pH}$ and organic matter (SOM), but also could significantly reduce the bioavailability of these metals. A low concentration of 2,4-dichlorophenol (2,4-DCP) could be removed with $\mathrm{Cd}$ or $\mathrm{Pb}$ immobilization. Simultaneous immobilization of $\mathrm{Cd}$ and $\mathrm{Pb}$ by $\mathrm{BC}-\mathrm{nZVI}$ was achieved, and the corresponding bioavailabilities also decreased. Several stable Cd and $\mathrm{Pb}$ species such as $\mathrm{CdCO}_{3}, \mathrm{Cd}(\mathrm{OH})_{2}, \mathrm{PbCO}_{3}$ and $\mathrm{Pb}(\mathrm{OH})_{2}$ were formed after BC-nZVI treatment. Cd immobilization by BC-nZVI was the adsorption and precipitation, whereas $\mathrm{Pb}$ immobilization was the adsorption, reduction and precipitation. Overall, our results suggest that BC-nZVI is an efficient amendment to immobilize $\mathrm{Cd}$ and $\mathrm{Pb}$ in soil and reduce their bioavailability associated with exposure risk.

Acknowledgements Prof. Wei Chu for encouragement and enthusiasm during this study.

Author contributions Wei Qian: Investigation, Conceptualization, 
381

382

383

Writing-original draft; Zeng-Hui Diao: Writing review \& editing, Supervision. All authors read and approved the final manuscript.

Funding This research was supported by the National Natural Science Foundation of China (No. 21407155) and Guangdong Provincial Key R\&D Programme (2020B1111350002).

Data and materials availability Not applicable

\section{Declarations}

Ethics approval and consent to participate Not applicable.

Consent for publication Not applicable.

Competing interests The authors declare no competing interests.

\section{References}

Awual MR., Khraisheh M, Alharthi NH., Luqman, M, Islamd A, Karim MR, Rahman MM, Khaleque MA (2018) Efficient detection and adsorption of cadmium(II) ions using innovative nano-composite materials. Chem. Eng. J. 343: 118-127.

Ahmad M, Ok YS, Kim BY, Ahn JH, Lee YH, Zhang M, Moon DH, AlWabel MI, Lee, SS (2016) Impact of soybean stover- and pine needle-derived biochars on $\mathrm{Pb}$ and as mobility, microbial community, and carbon stability in a contaminated agricultural soil. J. Environ. Manag. 166: 131-139.

Arshadi M, Soleymanzadeh M, Salvacion JWL, SalimiVahid F (2014) Nanoscale Zero-Valent Iron (NZVI) supported on sineguelas waste for $\mathrm{Pb}(\mathrm{II})$ removal from aqueous solution: Kinetics, thermodynamic and mechanism. J. Colloid. Interf. Sci. 426: $241-251$. 
Bian RJ, Joseph S, Cui L, Pan GX, Li LQ, Liu XY, Zhang A, Rutlidge H, Wong SW, Chia C, Marjo C, Gong B, Munroe P, Donne S, (2014) A three-year experiment confirms continuous immobilization of cadmium and lead in contaminated paddy field with biochar amendment. J. Hazard. Mater. 272: 121-128.

Bowman GM, Hutka J (2002) Soil Physical Measurement and Interpretation for Land Evaluation. Australian Soil and Land Survey Handbooks, CSIRO Publishing, Collingwood, Australia, pp. 224-239.

Cui LQ, Pan GX, Li LQ, Bian RJ, Liu XY, Yan JL, Quan GX, Ding C, Chen TM, Liu Y, Liu YM, Yin CT, Wei CP, Yang, YG., Hussain Q (2016) Continuous immobilization of cadmium and lead in biochar amended contaminated paddy soil: a five-year field experiment. Ecol. Eng. 93: 1-8.

Diao ZH, Du JJ, Jiang D, Kong LJ, Huo WY, Liu CM, Wu QH, Xu XR (2018) Insights into the simultaneous removal of $\mathrm{Cr}^{6+}$ and $\mathrm{Pb}^{2+}$ by a novel sewage sludgederived biochar immobilized nanoscale zero valent iron: coexistence effects and mechanism. Sci. Total. Environ. 642: 505-515.

Diao ZH, Yan L, Dong FX, Qian W, Deng QH, Kong LJ, Yang JW, Lei ZX, Du JJ, Chu W (2020) Degradation of 2,4-Dichlorophenol by a novel iron based system and its synergism with $\mathrm{Cd}(\mathrm{II})$ immobilization in a contaminated soil. Chem. Eng. J. 379: 122313.

Diao ZH, Qian W, Zhang ZW, Jin JC, Chen ZL, Guo PR, Dong FX, Yan L, Kong LJ, Chu W (2020) Removals of Cr(VI) and Cd(II) by a novel nanoscale zero valent iron/peroxydisulfate process and its Fenton-like oxidation of pesticide atrazine: 
Jia HZ, Wang CY (2012) Adsorption and dechlorination of 2,4-dichlorophenol (2,4-DCP) on a multi-functional organo-smectite templated zero-valent iron

Kumari M, Pittman Jr CU, Mohan D (2015) Heavy metals [chromium (VI) and lead

Li ZT, Wang L, Meng J, Liu XM, Xu JM, Wang F, Brookes P (2018) Zeolite-supported nanoscale zero-valent iron: New findings on simultaneous adsorption of $\mathrm{Cd}(\mathrm{II}), \mathrm{Pb}(\mathrm{II})$, and $\mathrm{As}(\mathrm{III})$ in aqueous solution and soil. J. Hazard. Mater. 344: 1-11.

Li H, Ye X, Geng Z, Zhou H, Guo X, Zhang Y, Zhao H, Wang G (2016) The influence of biochar type on long-term stabilization for $\mathrm{Cd}$ and $\mathrm{Cu}$ in contaminated paddy soils. J. Hazard Mater. 304: 40-48.

Lee SH, Lee JS, Choi YJ, Kim JG (2009) In situ stabilization of cadmium-, lead-, and zinc-contaminated soil using various amendments, Chemosphere 77: 1069-1075.

Lyu HH, Zhao H, Tang JC, Gong YY, Huang Y, Wu QH, Gao B (2018) Immobilization of hexavalent chromium in contaminated soils using biochar supported nanoscale iron sulfide composite. Chemosphere 194: 360-369.

Liu L, Liu X, Wang D, Lin H, Huang L (2020) Removal and reduction of Cr(VI) in simulated wastewater using magnetic biochar prepared by co-pyrolysis of nano-zero-valent iron and sewage sludge. J. Clean. Prod. 257: 120562. 
Liu, XY, Yang L, Zhao HT, Wang W (2020) Pyrolytic production of zerovalent iron nanoparticles supported on rice husk-derived biochar: simple, in situ synthesis and use for remediation of $\mathrm{Cr}(\mathrm{VI})$-polluted soils. Sci. Total Environ. 708: 134479.

Liu CM, Diao ZH, Huo WY, Kong LJ, Du JJ (2018) Simultaneous removal of $\mathrm{Cu}^{2+}$ and bisphenol A by a novel biochar-supported zero valent iron from aqueous solution:synthesis, reactivity and mechanism. Environ. Pollut. 239: 698-705.

Liu RQ, Zhao DY (2013) Synthesis and characterization of a new class of stabilized apatite nanoparticles and applying the particles to in situ $\mathrm{Pb}$ immobilization in a fire-range soil. Chemosphere 91: 594-601.

Liu JJ, Diao Z.H, Liu CM, Jiang D, Kong LJ, Xu XR (2018) Synergistic reduction of $\mathrm{Cu}^{2+}$ and oxidation of norfloxacin over a novel sewage sludge-derived char-based catalyst: performance, fate and mechanism. J. Clean. Prod. 182: 794804.

Mandal S, Pu SY, Wang XK, Ma H, Bai YC (2020) Hierarchical porous structure polysulfide supported nZVI/biochar and efficient immobilization of selenium in the soil. Sci. Total Environ. 708: 134831.

Mahar A, Wang P, Li R, Zhang Z (2015) Immobilization of lead and cadmium in contaminated soil using amendments: a review. Pedosphere 25: 555-568.

Ma JW, Wang FY, Huang ZH, Wang H (2010) Simultaneous removal of 2,4-dichlorophenol and $\mathrm{Cd}$ from soils by electrokinetic remediation combined with activated bamboo charcoal. J. Hazard. Mater. 176: 715-720. 
Nelson DW, Sommers LE (2001) Total carbon, organic carbon, and organic matter, in: Methods of Soil Analysis. Part 3-Chemical Methods. Soil Science Society of America, Inc., American Society of Agronomy, Inc., Madison, Wisconsin, USA, pp. 961-1010.

Puga AP, Abreu CA, Melo LCA, Beesley L (2015) Biochar application to a contaminated soil reduces the availability and plant uptake of zinc, lead and cadmium. J. Environ. Manag. 159: 86-93.

Qian TT, Wu P, Qin QY, Huang YN, Wang YJ, Zhou DM (2019) Screening of wheat straw biochars for the remediation of soils polluted with $\mathrm{Zn}$ (II) and Cd (II). J. Hazard. Mater. 362: 311-317.

Qian LB, Zhang WY, Yan JC, Han L, Chen Y, Ouyang D, Chen MF (2017) Nanoscale zero-valent iron supported by biochars produced at different temperatures: Synthesis mechanism and effect on Cr(VI) removal. Environ. Pollut. 223: 153160.

Qiao YX, Wu J, Xu YZ, Fang ZQ, Zheng LC, Cheng W, Tsang EP, Fang JZ, Zhao DY (2017) Remediation of cadmium in soil by biochar-supported iron phosphate nanoparticles. Ecol. Eng. 106: 515-522.

Qiao JT, Liu TX, Wang XQ, Li FB, Lv YH, Cui JH (2018) Simultaneous alleviation of cadmium and arsenic accumulation in rice by applying zerovalent iron and biochar to contaminated paddy soils. Chemosphere 195: 260-271.

Qiu Z, Tang JW, Chen JH, Zhang QZ (2020) Remediation of cadmium-contaminated soil with biochar simultaneously improves biochar's recalcitrance. Environ. 
492

493

494

495

496

497

498

499

500

501

502

503

504

505

506

507

508

509

510

511

512

Ren J, Wang FH, Zhai YB, Zhu Y, Peng C, Wang TF, Li CT, Zeng GM (2017) Effect of sewage sludge hydrochar on soil properties and $\mathrm{Cd}$ immobilization in a contaminated soil. Chemosphere 189: 627-633.

Rajapaksha AU, Chen SS, Tsang DCW, Zhang M, Vithanage M, Mandal S, Gao B, Bolan NS, Ok YS (2016) Engineered/designer biochar for contaminant removal/immobilization from soil and water: potential and implication of biochar modification. Chemosphere 148: 276-291.

Su HJ, Fang ZQ, Tsang PE, Zheng LC, Cheng W, Fang JZ, Zhao DY (2016) Remediation of hexavalent chromium contaminated soil by biochar-supported zero-valent iron nanoparticles. J. Hazard. Mater. 318: 533-540.

Shen ZT, McMillan O, Jin F, Al-Tabbaa A (2016) Salisbury biochar did not affect the mobility or speciation of lead in kaolin in a short-term laboratory study. J. Hazard. Mater. 316: 214-220.

Salam A, Bashir S, Khan I, Hu HQ, 2019. Two years impacts of rapeseed residue and rice straw biochar on $\mathrm{Pb}$ and $\mathrm{Cu}$ immobilization and revegetation of naturally co-contaminated soil. Appl. Geochem. 105: 97-104.

Tessier A, Campbell PGC, Bisson M (1979) Sequential extraction procedure for the speciation of particulate trace metals. Anal. Chem. 51: 844-851.

Tchounwou PB, Yedjou CG, Patlolla AK, Sutton DJ (2014) Heavy metals toxicity and the environment. PMC 26: 133-164.

Vítkova M, Puschenreiter M, Komarek M (2018) Effect of nano zero-valent iron 
application on $\mathrm{As}, \mathrm{Cd}, \mathrm{Pb}$, and $\mathrm{Zn}$ availability in the rhizosphere of metal(loid) contaminated soils. Chemosphere 200: 217-226.

Wang AQ, Zheng ZK, Li RQ, Hu D, Lu YR, Luo HX, Yan K (2019) Biomass-derived porous carbon highly efficient for removal of $\mathrm{Pb}(\mathrm{II})$ and $\mathrm{Cd}(\mathrm{II})$. Green. Energy \& Environ. 4: 414-423.

Wang T, Jin XY, Chen ZL, Megharaj M, Naidu R (2014) Simultaneous removal of $\mathrm{Pb}(\mathrm{II})$ and $\mathrm{Cr}(\mathrm{III})$ by magnetite nanoparticles using various synthesis conditions. J. Ind. Eng. Chem. 20: 3543-3549.

Wang L, Cho DW, Tsang DCW, Cao XD, Hou DY, Shen ZT, Alessi DS Ok YS, Poon CS (2019) Green remediation of As and $\mathrm{Pb}$ contaminated soil using cement-free claybased stabilization/solidification. Environ. Int. 126: 336-345.

Weng XL, Jin XY, Lin JJ, Naidu R, Chen ZL (2016) Removal of mixed contaminants $\mathrm{Cr}(\mathrm{VI})$ and $\mathrm{Cu}(\mathrm{II})$ by green synthesized iron based nanoparticles. Ecol. Eng. 97: $32-39$.

Wang SS, Zhao MY, Zhou M, Lia YCC, Wang J, Gao B, Sato S, Feng K, Yin WQ, Deshani Igalavithana A, Oleszczuk P, Wang XZ, Ok YS (2019) Biochar-supported nZVI (nZVI/BC) for contaminant removal from soil and water: a critical review. J. Hazard. Mater. 373: 820-834.

Wang Y, Wang L, Deng X, Gao H (2020) A facile pyrolysis synthesis of biochar/ZnO passivator: immobilization behavior and mechanisms for $\mathrm{Cu}(\mathrm{II})$ in soil. Environ. Sci. Pollut. Res. 27: 1888-1897.

Yin DX, Wang X, Chen C, Peng B, Tan CY, Li HL (2016) Varying effect of biochar 
on $\mathrm{Cd}, \mathrm{Pb}$ and $\mathrm{As}$ mobility in a multi-metal contaminated paddy soil. Chemosphere 152: 196-206.

537

Yang ZM, Fang ZQ, Zheng LC, Cheng W, Tsang PE, Fang JZ, Zhao DY (2016) Remediation of lead contaminated soil by biochar-supported nano-hydroxyapatite. Ecotox. Environ. Safe. 132: 224-230.

Yang Q, Li Z, Lu X, Duan Q, Huang L, Bi J (2018) A review of soil heavy metal pollution from industrial and agricultural regions in China: pollution and risk assessment. Sci. Total Environ. 642: 690-700.

Yang T, Han C, Tang J, Luo Y (2020) Removal performance and mechanisms of $\mathrm{Cr}(\mathrm{VI})$ by an in-situ self-improvement of mesoporous biochar derived from chicken bone. Environ. Sci. Pollut. Res. 27: 5018-5029.

Zhu F, Li LW, Ma SY, Shang ZF (2016) Effect factors, kinetics and thermodynamics of remediation in the chromium contaminated soils by nanoscale zero valent Fe/Cu bimetallic Particles. Chem. Eng. J. 302: 663-669.

Zhang S, Lyu HH, Tang JC, Song B, Zhen M, Liu X (2019) A novel biochar supported CMC stabilized nano zero-valent iron composite for hexavalent chromium removal from water. Chemosphere 217: 686-694.

Zhou YM, Gao B, Zimmerman AR, Chen H, Zhang M, Cao XD (2014) Biochar-supported zerovalent iron for removal of various contaminants from aqueous solutions. Bioresour. Technol. 152: 538-542. 

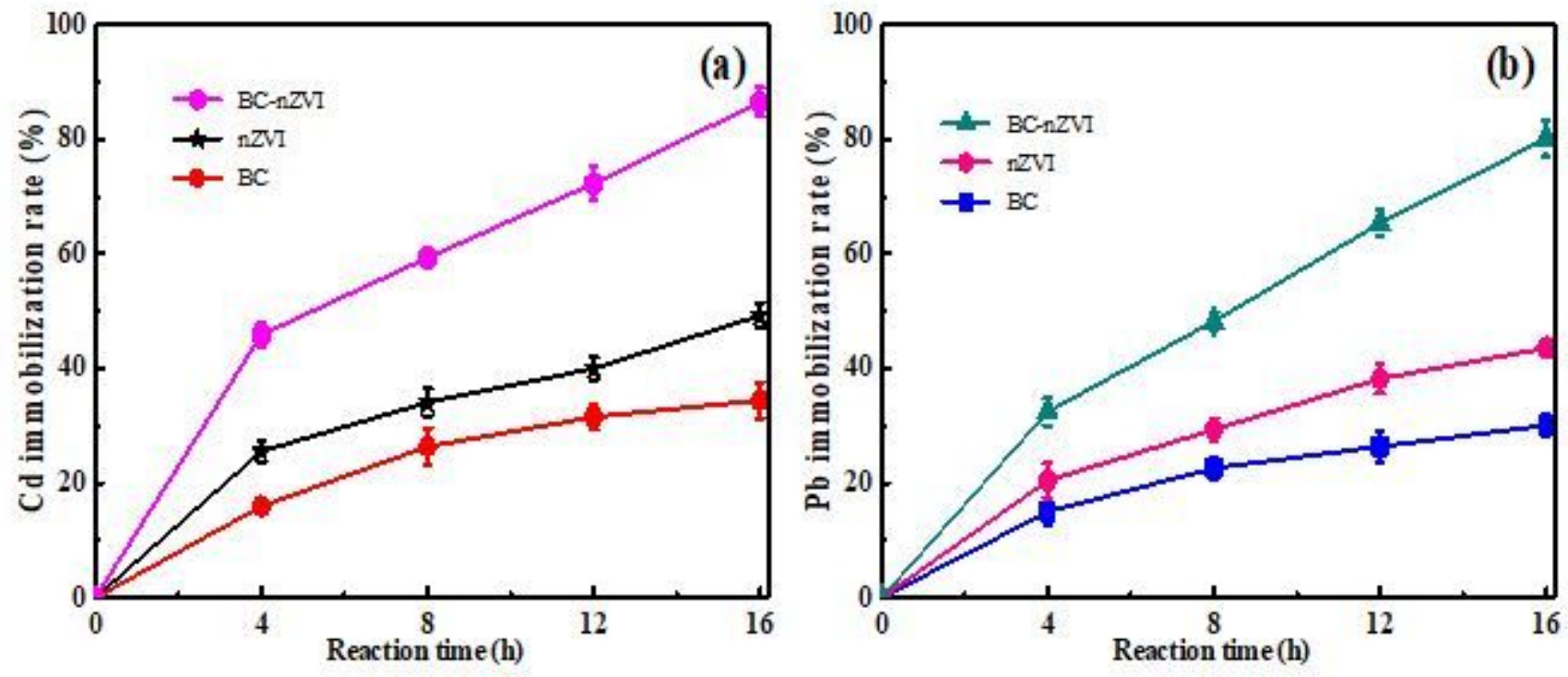

Figure 1

Immobilization efficiency of $\mathrm{Cd}$ and $\mathrm{Pb}$ by different amendments. Reaction conditions: [Cd] $0=9.86$ $\mathrm{mg} / \mathrm{kg},[\mathrm{Pb}] 0=101.32 \mathrm{mg} / \mathrm{kg},[\mathrm{BC}, \mathrm{nZVI}$ or BC-nZVI] $0=2.0 \mathrm{~g} / \mathrm{L}, \mathrm{pH}=6.54 \pm 0.02$.
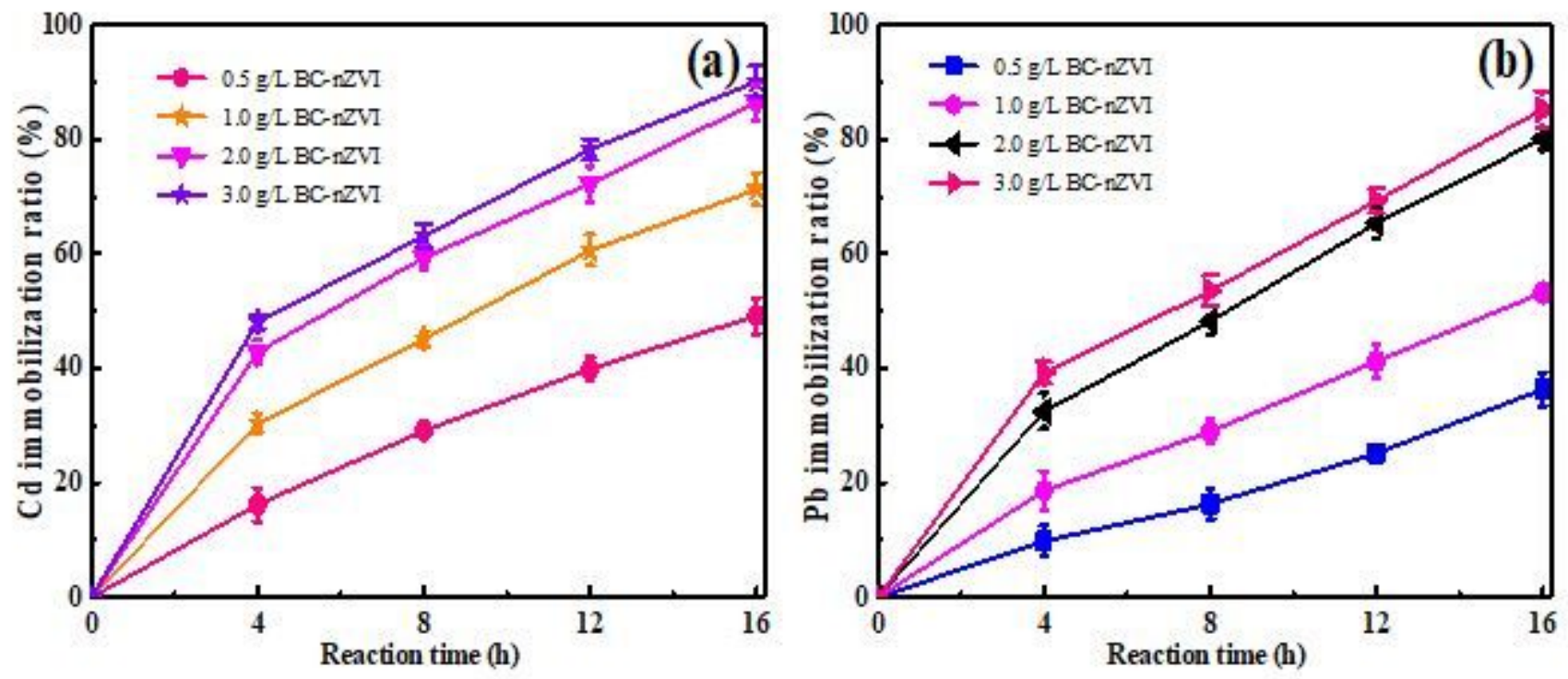

Figure 2

Effect of BC-nZVI dosage on the immobilization of $\mathrm{Cd}$ and $\mathrm{Pb}$. Reaction conditions: $[\mathrm{Cd}] 0=9.86 \mathrm{mg} / \mathrm{kg}$, $[\mathrm{Pb}] 0=101.32 \mathrm{mg} / \mathrm{kg},[\mathrm{BC}-\mathrm{nZVI}] 0=0.5-3.0 \mathrm{~g} / \mathrm{L}, \mathrm{pH}=6.54 \pm 0.02$. 


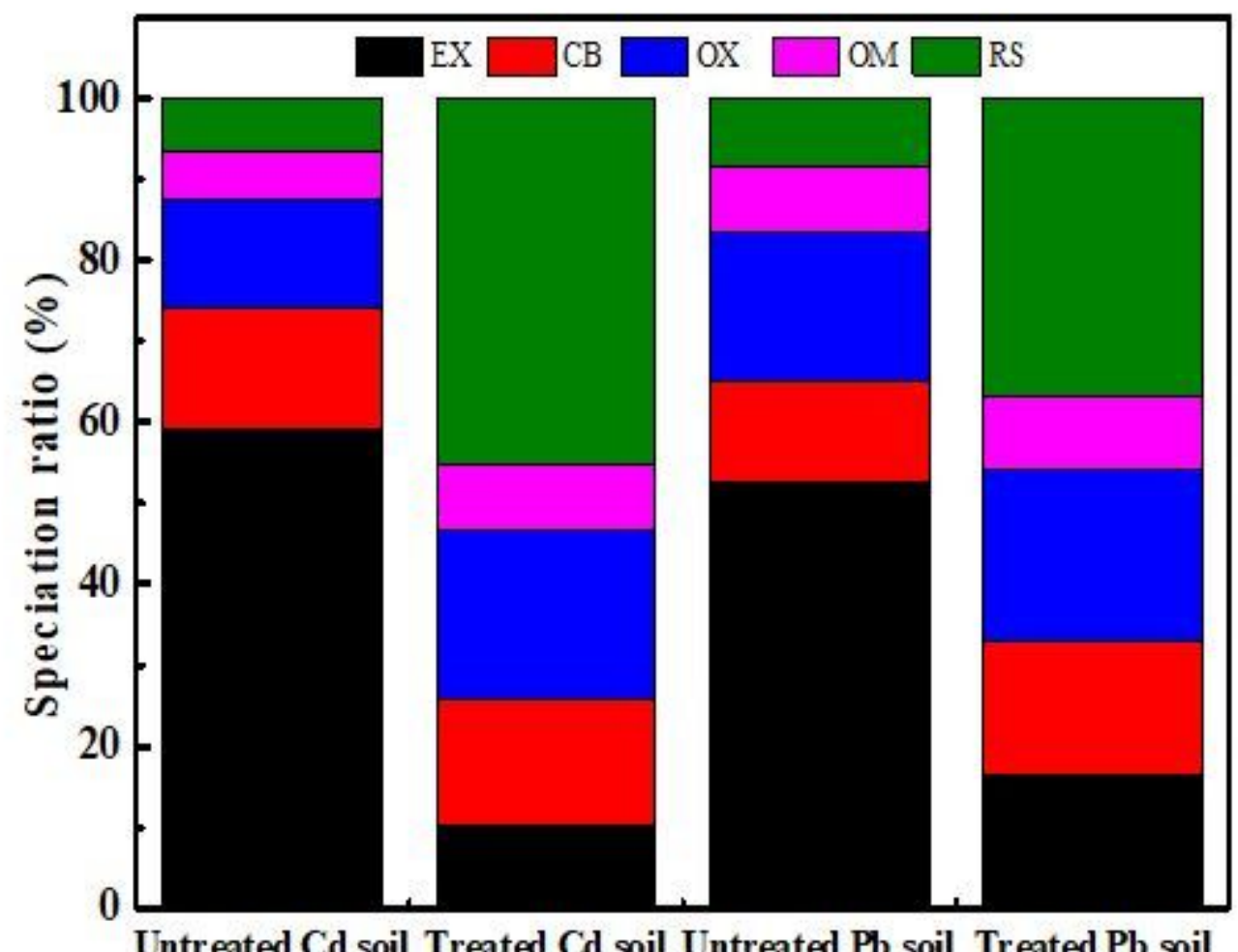

Figure 3

Bioavailability fraction of $\mathrm{Cd}$ or $\mathrm{Pb}$ in soil before and after remediation. Reaction conditions: $[\mathrm{Cd}] 0=9.86$ $\mathrm{mg} / \mathrm{kg},[\mathrm{Pb}] 0=101.32 \mathrm{mg} / \mathrm{kg},[B C-\mathrm{nZVI}] 0=2.0 \mathrm{~g} / \mathrm{L}, \mathrm{pH}=5.64 \pm 0.02$.
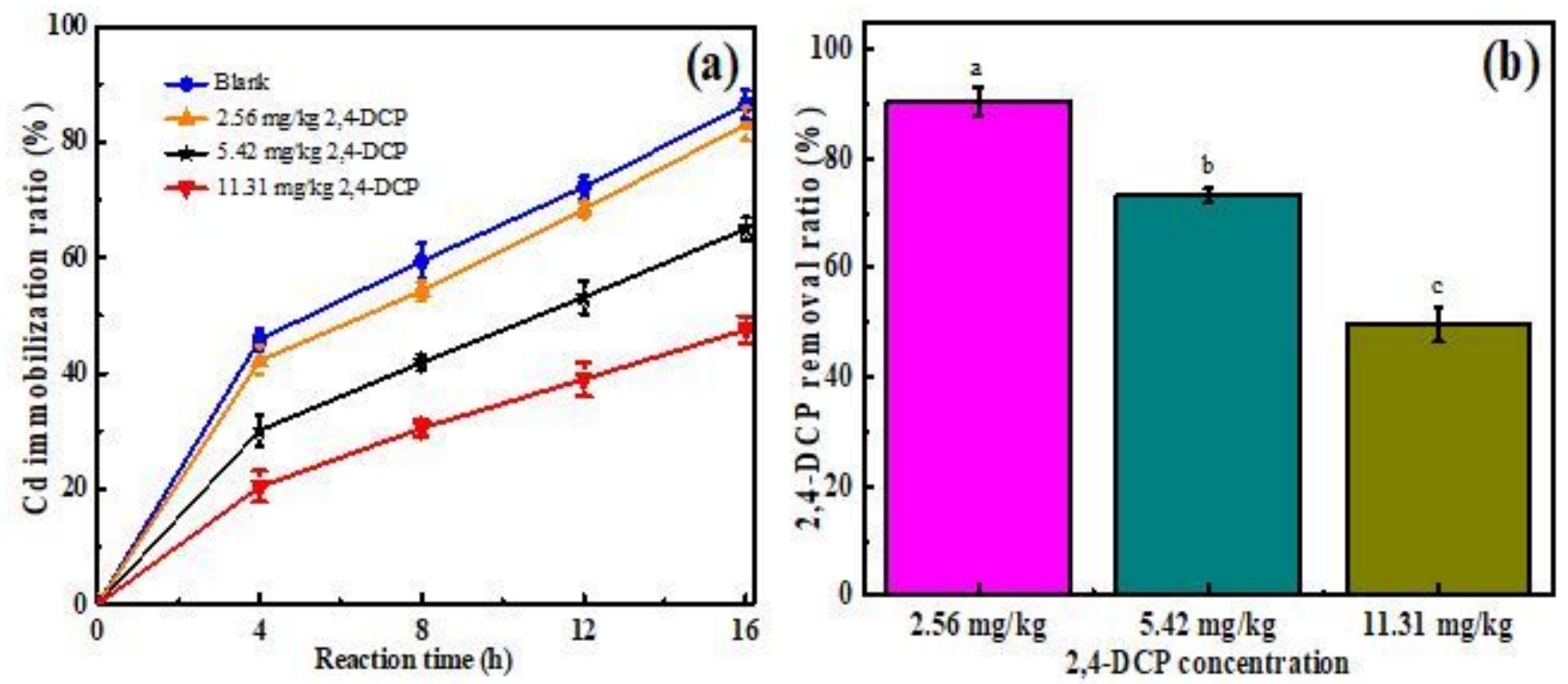

Figure 4

Effect of 2,4-DCP concentrations on Cd immobilization, (a) Cd immobilization; (b) 2,4-DCP removal. Reaction conditions: $[\mathrm{Cd}] 0=9.86 \mathrm{mg} / \mathrm{kg},[2,4-\mathrm{DCP}] 0=0-11.31 \mathrm{mg} / \mathrm{kg},[\mathrm{BC}-\mathrm{nZVI}] 0=2.0 \mathrm{~g} / \mathrm{L}, \mathrm{pH}=6.54 \pm 0.02$. 

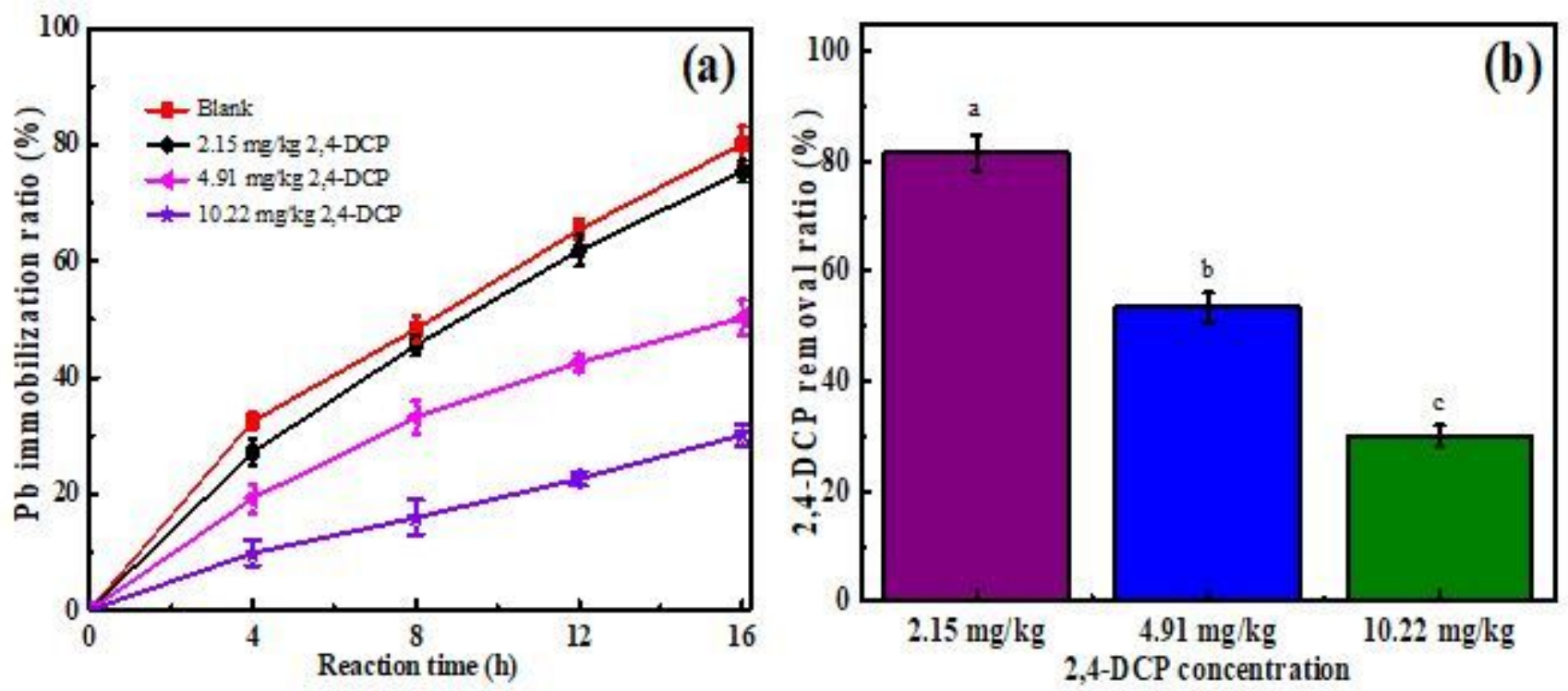

Figure 5

Effect of 2,4-DCP concentrations on Pb immobilization, (a) Pb immobilization; (b) 2,4-DCP removal. Reaction conditions: $[\mathrm{Pb}] 0=101.32 \mathrm{mg} / \mathrm{kg},[2,4-\mathrm{DCP}] 0=0-10.22 \mathrm{mg} / \mathrm{kg},[B C-\mathrm{nZVI}] 0=2.0 \mathrm{~g} / \mathrm{L}, \mathrm{pH}=$ $6.54 \pm 0.02$.
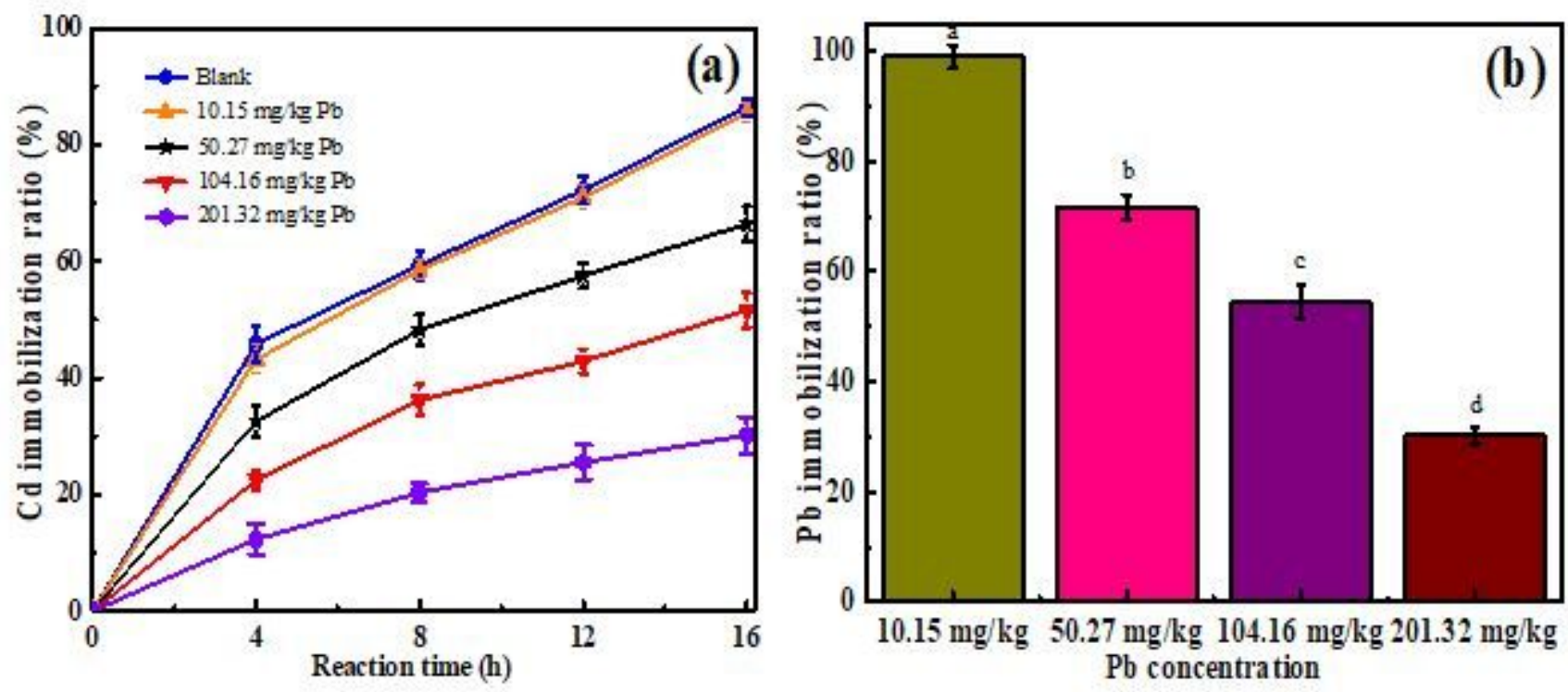

Figure 6

Simultaneous immobilization efficiencies of $\mathrm{Cd}$ and $\mathrm{Pb}$ in soil. Reaction conditions: [Cd] $0=10.26 \mathrm{mg} / \mathrm{kg}$, $[\mathrm{Pb}] 0=0-201.32 \mathrm{mg} / \mathrm{kg},[\mathrm{BC}-\mathrm{nZV} \mathrm{Vl}] 0=2.0 \mathrm{~g} / \mathrm{L}, \mathrm{pH}=6.54 \pm 0.02$. 


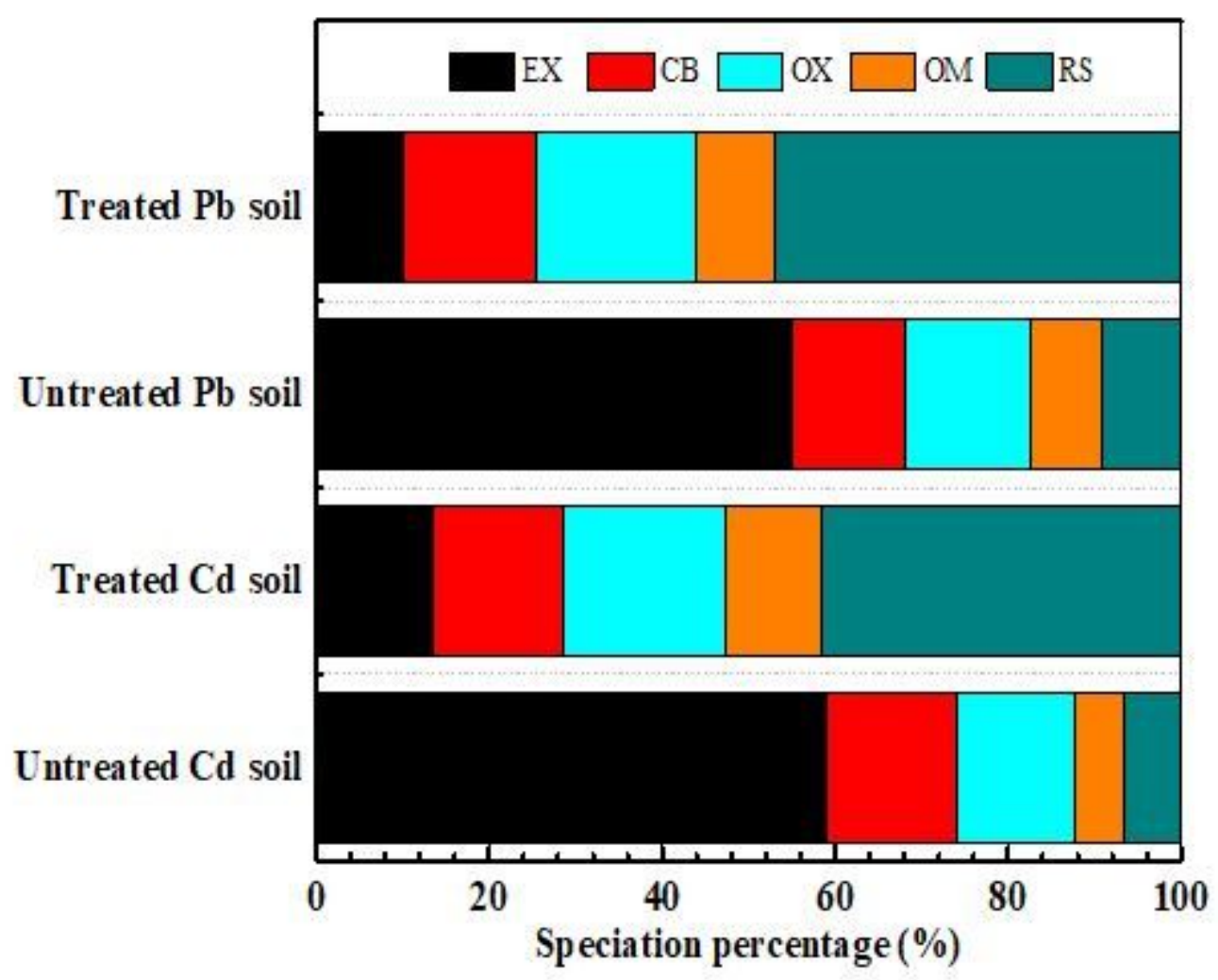

Figure 7

Bioavailability fractions of $\mathrm{Cd}$ and $\mathrm{Pb}$ in soil before and after remediation. Reaction conditions: [Cd] $0=$ $9.86 \mathrm{mg} / \mathrm{kg},[\mathrm{Pb}] 0=10.15 \mathrm{mg} / \mathrm{kg},[\mathrm{BC}-\mathrm{nZV} \mathrm{V}] 0=2.0 \mathrm{~g} / \mathrm{L}, \mathrm{pH}=6.54 \pm 0.02$. 

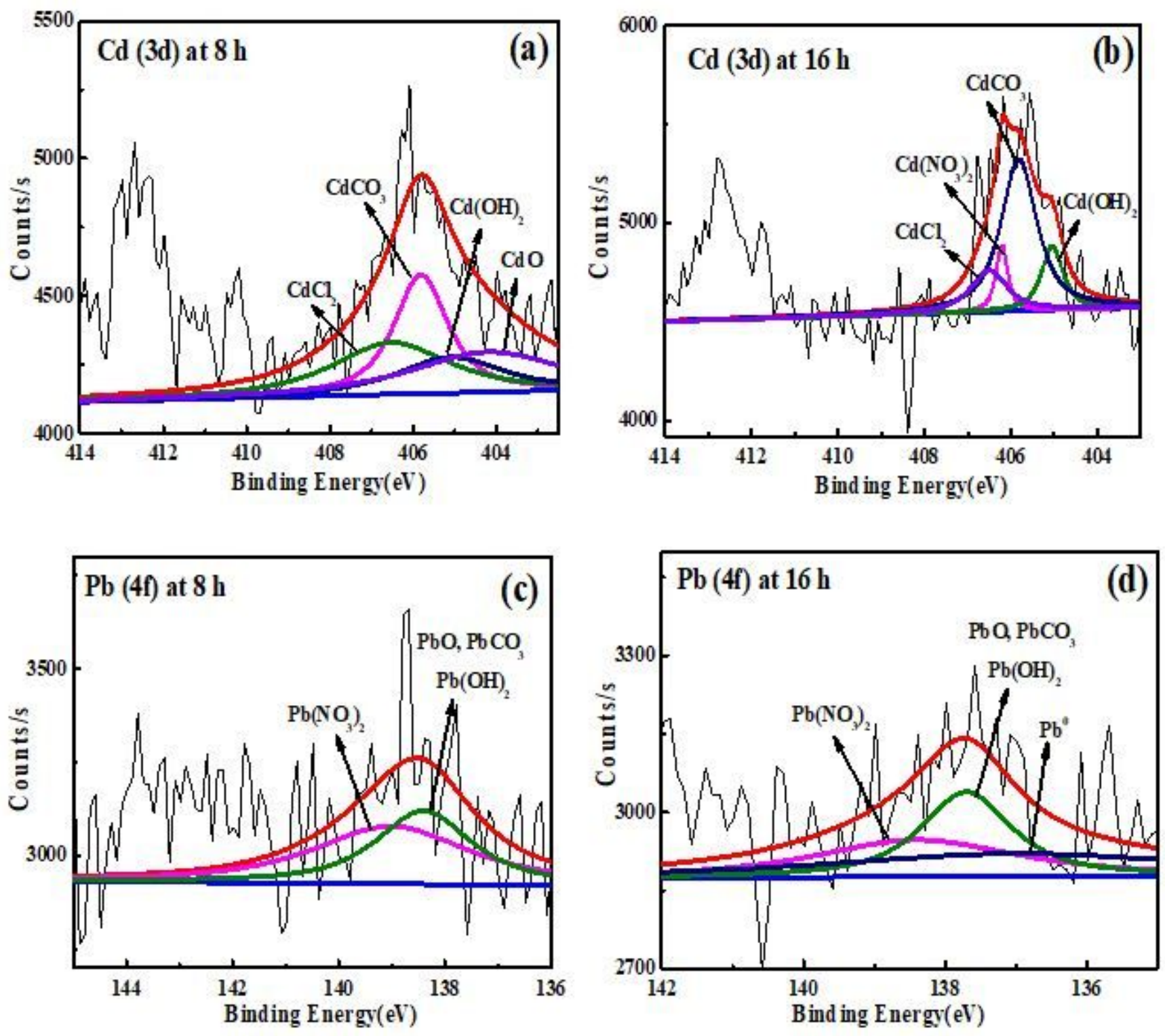

Figure 8

XPS spectra variations of $\mathrm{Cd}(3 \mathrm{~d})$ and $\mathrm{Pb}(4 \mathrm{f})$ during the reaction. 

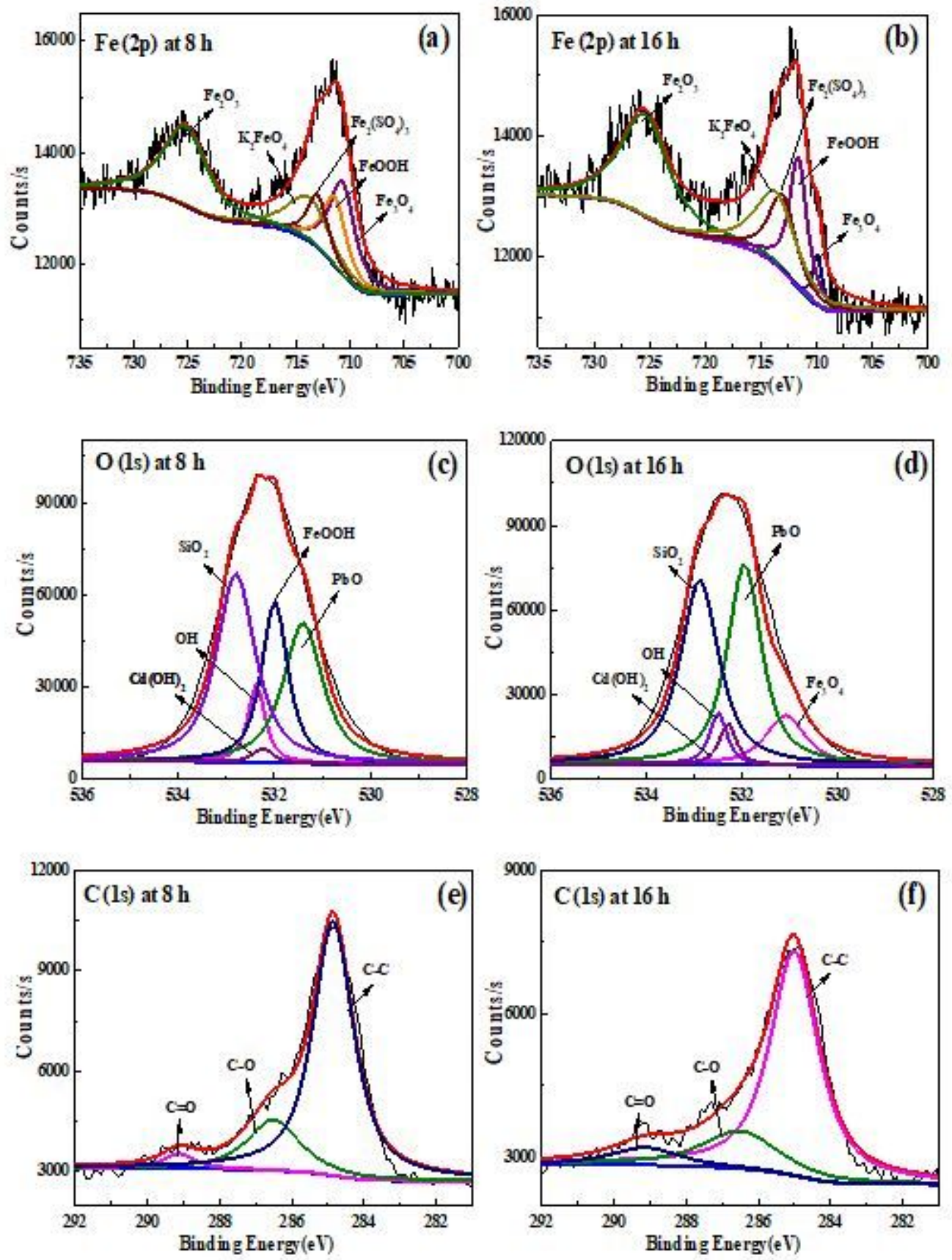

Figure 9

XPS spectra variations of $\mathrm{Fe}(2 \mathrm{p}), \mathrm{O}(1 \mathrm{~s})$ and $\mathrm{C}(1 \mathrm{~s})$ during the reaction. 


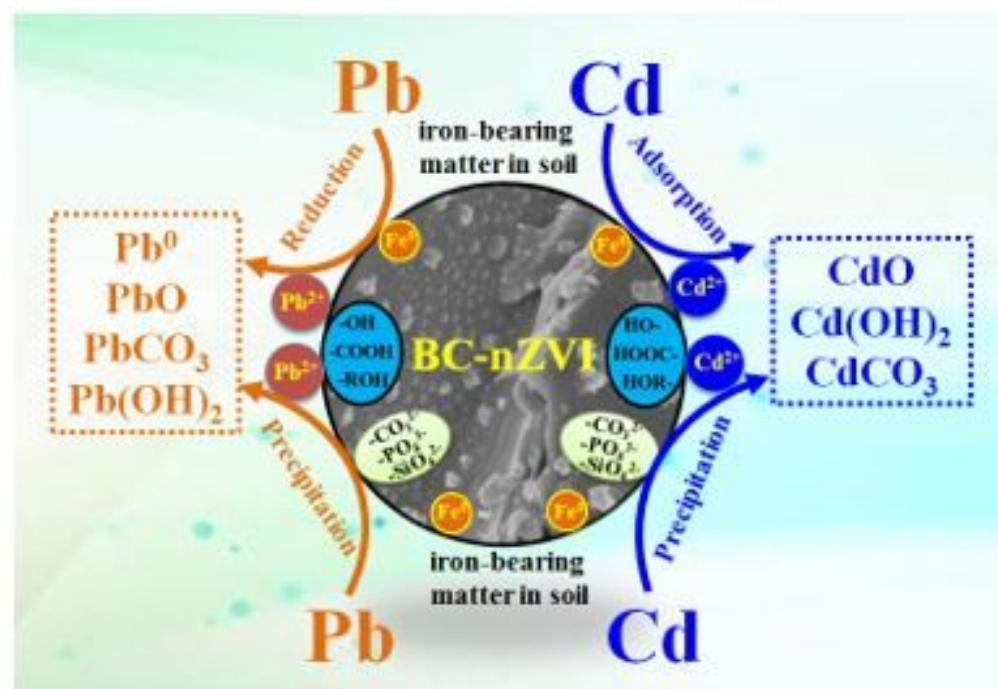

Figure 10

The reaction mechanism for $\mathrm{Cd}$ and $\mathrm{Pb}$ immobilization in soil by $\mathrm{BC}-\mathrm{Nzvi}$.
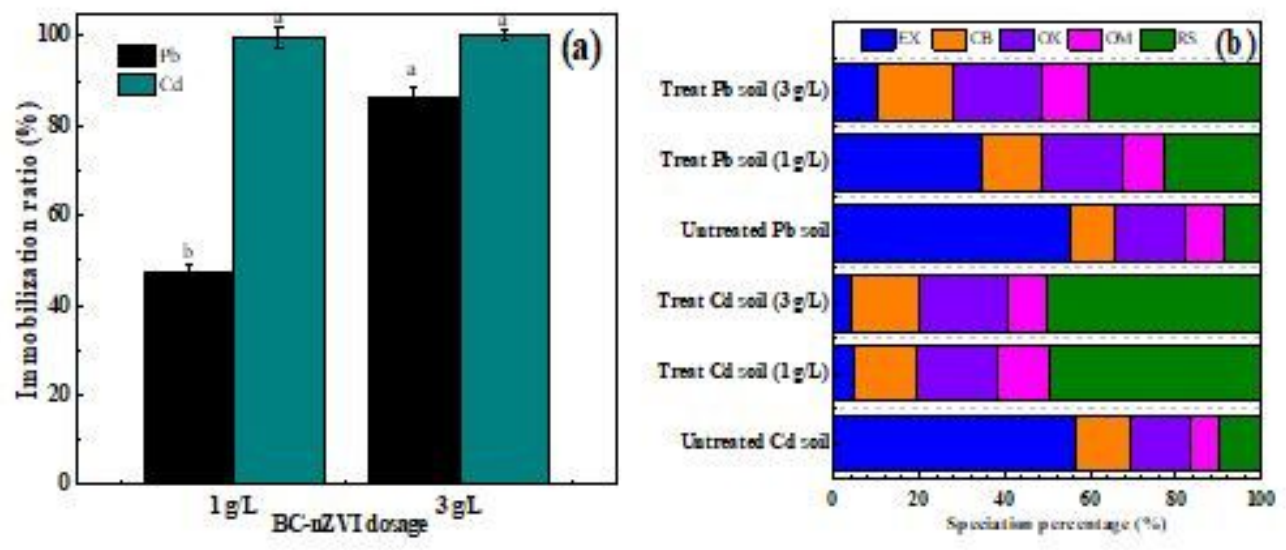

Figure 11

Remediation of $\mathrm{Cd}$ and $\mathrm{Pb}$ in real contaminated soil by $\mathrm{BC}-\mathrm{nZVI}$. Reaction conditions: $[\mathrm{Cd}] 0=2.53 \mathrm{mg} / \mathrm{kg}$, $[\mathrm{Pb}] 0=167.12 \mathrm{mg} / \mathrm{kg},[\mathrm{BC}-\mathrm{nZVI}] 0=1.0$ and $3.0 \mathrm{~g} / \mathrm{L}, \mathrm{pH}=6.08 \pm 0.02$.

\section{Supplementary Files}

This is a list of supplementary files associated with this preprint. Click to download.

- SupplementaryMaterials0220.docx 